\title{
Analisis Hubungan Tingkat Kesegaran Jasmani terhadap Hasil Belajar Siswa
}

Ikhwan Abduha, Humaedib, Muhammad Agusmanc

abc Universias Tadulako, Indonesia

Correspondence: ikhwan.abduh09@gmail.com

Received: 22 Jun 2020 Accepted: 26 Jul 2020 Published: 31 Oct 2020

\begin{abstract}
Student academic problems have always been a concern of the government and teachers, various methods and design of learning that are used in improving academic achievement and student learning outcomes. This study examines the relationship of physical fitness to student learning outcomes. The number of samples 28 people selected from the population of 35 people with purposive sampling technique. Data collection techniques using 5 physical fitness test instruments and for learning outcomes taken from the results of midterm exams. Data analysis techniques used the Kolmogorof Smirnof One Sample Test and Pearson Spearman Correlation Test. The results showed that the highest physical fitness score of 24 was included in the very good category and the lowest score was 13 , which means it was still lacking, the highest average student learning outcomes were 79.92 and the lowest average value was 72.28 . While the Correlation analysis shows the value $(\mathrm{r}) 0.304$ with a probability level $(0.005)<\alpha 0.05$ so there is a significant relationship between the two variables. Based on the analysis it is concluded that there is a relationship between the level of physical fitness with student learning outcomes, the better the physical fitness, the better the student learning outcomes will be.
\end{abstract}

Keywords: learning outcomes; physical fitness; student

\begin{abstract}
Abstrak
Masalah akademik siswa selalu menjadi konsen pemerintah maupun guru, berbagai macam metode dan desain pembelajaran yang digunakan dalam meningkatkan prestasi akademik dan hasil belajar siswa. Penelitian ini mengkaji tentang hubungan kesegaran jasmani terhadap hasil belajar siswa. Jumlah sampel 28 orang yang dipilih dari populasi sebanyak 35 orang dengan teknik purposive sampling. Teknik pengumpulan data menggunakan 5 instrumen tes kesegaran jasmani dan untuk hasil belajar diambil dari hasil ujian tengah semester. Teknik analisis data menggunakan uji one sample kolmogorov smirnov dan uji korelasi spearman. Hasil penelitian menunjukkan bahwa nilai tertinggi tes kesegaran jasmani sebesar 24 nilai tersebut sudah termasuk pada kategori sangat baik dan nilai terendah 13 yang berarti masih berkategori kurang, rata-rata tertinggi hasil belajar siswa 79.92 dan nilai rata-rata terendah 72,28. Sedangkan analisis Korelasi menunjukkan nilai (r) 0,304 dengan tingkat probabilitas $(0.005)<\alpha 0.05$ sehingga terdapat hubungan yang signifikan antar kedua variable. Berdasarkan analisis disimpulkan bahwa ada hubungan tingkat kesegaran jasmani dengan hasil belajar siswa, semakin baik kesegaran jasmani, maka akan menunjang hasil belajar siswa.
\end{abstract}

Kata kunci: hasil belajar; kesegaran jasmani; siswa 


\section{Pendahuluan}

Pendidikan secara umum hendaknya memperhatikan secara global tentang kebutuhan siswa dan mampu memberikan pemecahan masalah yang timbul dari berbagai aspek kehidupan. Penyelenggaraan pendidikan dewasa ini sudah mulai melihat dari sudut pandang siswa sebagai member dan industri sebagai pengguna. Olehnya itu semua hal yang mendukung aktivitas belajar siswa sudah harus menjadi focus utama baik pemerintah maupun guru sebagai pengajar. Salah satu kebutuhan siswa dalam menunjang aktivitas akademik adalah kesegaran jasmani. Berbagai macam metode digunakan oleh guru pendidikan jasmani untuk meningkatkan kesegaran jasmani siswa misalnya menjadikan kegiatan outbound sebagai metode pembelajaran karena outbound terbukti dapat meningkatkan kesegaran jasmani siswa (Humaedi et al., 2019).

Selain itu, salah satu cara yang biasanya dilakukan dalam menjaga tingkat kesegaran jasmani yaitu dengan berolahraga. Olahraga memiliki beragam manfaat, diantaranya meningkatkan kesegaran jasmani. Dengan berolahraga, masyarakat dapat berguna dan manfaat bagi kesehatannya. Manfaat dari olahraga diharapkan masyarakat akan mampu bekerja yang lebih produktif, kebal terhadap penyakit, semangat dalam proses belajar, serta dapat berprestasi secara lebih optimal karena didukung oleh fisik yang prima.

Kesegaran jasmani merupakan potensi yang sangat penting dalam menunjang aktivitas sehari-hari tanpa merasa keletihan yang berlebih bahkan mampu melakukan aktivitas setelahnya. Melalui kegiatan fisik yang terarah dan dilakukan dengan kontinyu maka akan menghasilkan dampak kesegaran jasmani dan kesehatan (Singh \& Bhatti, 2020). Kesegaran jasmani merupakan hasil kerja dari fungsi system tubuh yang mewujudkan peningkatan kualitas kehidupan dalam setiap aktivitas yang melibatkan fisik. Aktivitas fisik dan olahraga yang dilakukan dengan intens, maka akan berbanding lurus dengan tingkat kesegaran jasmaninya (Alamsyah et al., 2017; Irhas \& Anna, 2014). Selain itu dengan melakukan aktivitas yang melibatkan fisik atau berolahraga akan berpengaruh terhadap kemampuan fisik dalam memaksimalkan oksigen yang diolah dalam tubuh. Jika tubuh telah memiliki kemampuan untuk memaksimalkan konsumsi oksigen serta mampu memenuhi nutrisi atau gizi yang baik maka akan berdampak signifikan terhadap kesegaran jasmaninya (Md Azmi \& Abdul Razak, 2020; Sepriadi et al., 2017; Welis \& Muhamad, 2010).

Sekolah Menengah Atas Olahraga (SMANOR) Tadulako Sulawesi Tengah adalah lembaga pendidikan yang mendidik anak berbakat dalam bidang olahraga. Pembinaan dilakukan dengan terprogram dan terkontrol baik dari segi porsi latihan maupun asupan gizi yang dikonsumsi siswa. Prestasi siswa dalam bidang keolahragaan sudah memadai, misalnya baru-baru ini salah siswa SMANOR atas nama Rio Riski Darmawan telah meraih medali emas pada Asean Games tahun 2018 pada cabang olahraga dayung dan banyak lagi prestasi lain yang telah diraih, capaian prestasi tersebut pastinya ditunjang dengan tingkat kebugaran fisik siswa. Hal yang terkadang menjadi pertanyaan adalah apakah dengan terprogramnya porsi latihan, asupan gizi dan pencapaian prestasi dibidang olahraga lantas akan berkorelasi dengan meningkatkan hasil belajar akademik siswa disekolah.

Sebuah studi dilakukan oleh (Gil et al., 2020) yang mengkaji tentang kesegaran jasmani serta hubungannya dengan prestasi akademik. Dalam penelitian ini kesegaran jasmani diukur dengan 3 komponen yaitu kebugaran kardiorespirasi, kekuatan otot dan fleksibilitas. Penggunaan sampel dalam penelitian tersebut memang lebih banyak dibandingkan penelitian yang dilakukan namun perbedaan dengan penelitian yang dilakukan adalah terdapat 5 komponen tes dan mencakup didalamnya tes kecepatan yang diukur dengan tes lari 60 meter dan tes kecepatan belum dilakukan pada penelitian tersebut. Studi lain juga dilakukan oleh (Perez, 2019) yang mengkaji hubungan kesegaran jasmani terhadap prestasi akademik pada kalangan perempuan yang diduga lebih mudah mengalami obesitas yang berdampak pada kesegaran jasmani dan prestasi akademiknya, perbedaan pada penelitian yang dilakukan adalah penggunaan sampel pada semua gender yakni baik laki-laki 
maupun perempuan dengan jenis tes kesegaran yang berbeda antar kedua jenis gender. Studi yang dilakukan (Han, 2018) menemukan bahwa siswa dengan tingkat kebugaran fisik yang baik cenderung memiliki skor rata-rata yang baik pada mata pelajaran dengan tingkat kerumitan yang lebih tinggi misalnya bahasa Inggris, matematika, dan sains. Hasil studi tersebut mengindikasikan bahwa aktivitas fisik yang intens mendorong perubahan otak yang terlihat dengan peningkatan oksigenasi dan jaringan, serta peningkatan aktivitas metabolism dan memberikan peningkatan perkembangan neurologis. Siklus tersebut menandakan bahwa aktivitas fisik menjadi factor penentu dalam pencapaian prestasi akademik.

Penelitian ini diharapkan dapat memberi dampak terhadap pengetahuan atlet, guru maupun pelatih bahwa indicator kesegaran jasmani dapat dijadikan perhatian sehingga dapat membuat model latihan atau model pembelajaran yang lebih mengedepankan aktivitas fisik yang menunjang kesegaran jasmani. Selain itu hasil penelitian dapat diaplikasikan terhadap system penerimaan siswa baru dengan harapan potensi prestasi akademik dan pembinaan prestasi olahraga bisa dapat lebih mudah diraih apabila siswa memiliki kesegaran jasmani yang baik.

\section{Metode Penelitian}

Jenis penelitian yang akan dilakukan adalah jenis penelitian dengan pendekatan korelatif (Arifin, 2011). Populasi adalah siswa Sekolah Menengah Atas Negeri Olah Raga cabang olahraga sepak takraw sebanyak 35 orang, sampel yang digunakan sebanyak 28 dengan teknik pengambilan sampel menggunakan teknik purposive sampling dengan pertimbangan usia 16-18 tahun dan tidak memiliki riwayat penyakit kardiorespirasi dan gangguan ginjal.

Mekanisme pengumpulan data dilakukan dengan beberapa tahapan dan berbeda antara sampel putra dan putri. 1) Untuk putra : a)lari 60 meter (16-19 tahun), b) Gantung angkat tubuh (pull up) selama 60 detik, c)Baring duduk (sit up) selama 60 detik, d)Loncat tegak (vertical jump). e) lari 1200 M. 2)Untuk putri : a) lari 60 meter, b) Gantung siku tekuk ( tahan pull up) selama 60 detik, c)Baring duduk (sit up) selama 60 detik, d)Loncat tegak (vertical jump), e) lari 1000 M (Pusat Pengembangan Kualitas Jasmani, 2010). Sedangkan pengambilan data prestasi akademik dinilai berdasarkan nilai sekolah (Gil et al., 2020), secara khusus nilai sekolah yang dianalisis adalah nilai tengah semester berjalan dengan 14 mata pelajaran yaitu mata pelajaran geografi, sejarah, pendidikan jasmani, matematika, ekonomi, bahasa Indonesia,. bahasa inggris, prakarya, pendidikan agama, seni, kimia, biologi, IPS dan PPKN.

Teknik analisis data dan prosedur penentuan skor kesegaran jasmani dilakukan dengan mentabulasi data tes pengukuran kesegaran jasmani kemudian dikonversi pada nilai norma tes kesegaran jasmani (Pusat Pengembangan Kualitas Jasmani, 2010), sedangkan nilai prestasi akademik diambil nilai ratarata secara keseluruhan dari ke 14 mata pelajaran tersebut (Gil et al., 2020). Teknik analisis data yang dilakukan terdiri dari beberapa tahapan diantaranya uji deskriptif, uji linieritas, perhitungan rata-rata (Mean), uji normalitas data dengan one sample kolmogorov smirnov test (Zhang et al., 2019), dan uji korelasi spearman (Schober et al., 2018). Untuk menentukan kuat atau lemahnya korelasi antar kedua variabel maka digunakan skala interval nilai korelasi 0,80- 0,80 - 1,00 : Sangat tinggi, 0,60 0,80 : Tinggi, 0,40 - 0,60: Cukup, 0,20 - 0,40 : Rendah, 0,00 - 0, 20 : Sangat rendah (Wahana, 2019).

\section{Hasil}

Berdasarkan hasil pengukuran tes kesegaran jasmani (TKJI) dan penilaian prestasi akademik pada kelas X Mea 1 SMANOR Tadulako Palu dapat dijabarkan pada tabel 1. 
Tabel 1. Deskriptif Kesegaran Jasmani dan Prestasi Akademik Siswa (n=28)

\begin{tabular}{clcccc}
\hline No & Komponen & $\begin{array}{c}\text { Skor } \\
\text { Minimal }\end{array}$ & $\begin{array}{c}\text { Skor } \\
\text { Maksimal }\end{array}$ & Rerata & SD \\
\hline 1 & Skor Kesegaran Jasmani Secara & 13.00 & 24.00 & 17.4286 & 2.28406 \\
& Keseluruhan** & 6.45 & 12.02 & 9.1714 & 1.30837 \\
2 & Kecepatan (lari 60 meter) & 3.00 & 34.00 & 17.2757 & 7.88287 \\
3 & Kekuatan Otot Lengan & & & & \\
& (Gantung angkat tubuh) & 13.00 & 60.00 & 36.0357 & 11.48746 \\
4 & Daya Tahan Otot Perut & & & & \\
& (Baring Duduk) & 32.00 & 80.00 & 54.8214 & 12.94162 \\
5 & Daya Ledak Otot Tungkai & & & & \\
& (Loncat Tegak) & 3.28 & 5.60 & 4.4821 & 0.56229 \\
6 & Daya Tahan Kardiovascular & & & & \\
& 1000/1200) & 71.00 & 77.00 & 72.2857 & 1.27242 \\
2 & Geografi & 71.00 & 77.00 & 72.8214 & 1.56474 \\
7 & Sejarah & 76.00 & 87.00 & 80.7500 & 2.92657 \\
8 & PJOK & 75.00 & 81.00 & 77.2143 & 1.75028 \\
9 & Matematika & 75.00 & 85.00 & 77.8571 & 2.73136 \\
10 & Ekonomi & 72.00 & 80.00 & 76.1786 & 2.73595 \\
11 & Bahasa Indonesia & 70.00 & 85.00 & 73.4643 & 3.22585 \\
12 & Bahasa Inggris & 78.00 & 80.00 & 78.5357 & 0.88117 \\
13 & Prakarya & 83.00 & 92.00 & 87.8214 & 2.01942 \\
14 & Pendidikan Agama & 77.00 & 88.00 & 79.5000 & 2.72845 \\
15 & Seni & 76.00 & 79.00 & 78.1429 & 0.93152 \\
16 & Kimia & 79.00 & 86.00 & 82.3929 & 2.36235 \\
17 & Biologi & 76.00 & 80.00 & 78.0357 & 1.10494 \\
18 & IPS & 78.00 & 83.00 & 79.9286 & 1.67616 \\
19 & PKN & & & & \\
\hline
\end{tabular}

$\mathrm{SD}=$ standar deviation. **Penentuan skor kesegaran jasmani berdasarkan norma penilaian (Pusat Pengembangan Kualitas Jasmani, 2010)

Analisis deskriptif skor kesegaran jasmani dari 28 sampel secara umum menunjukkan nilai rata-rata 17.4286 dengan nilai standar deviasi 2.28406 (tabel 1). Sedangkan dari 14 mata pelajaran yang diambil nilainya sebagai indikator penilaian prestasi belajar, nilai mata pelajaran pendidikan agama yang memiliki skor yang paling tinggi yaitu 92.00 (tabel 1) dan nilai mata pelajaran yang paling rendah adalah geografi dan sejarah yang memiliki nilai yang sama yaitu 71.00 (tabel 1).

Tabel 2. One Sample Kolmogorof Smirnov Tes

\begin{tabular}{lcc}
\hline & Prestasi belajar & Kesegaran jasmani \\
\hline Tes Statistik & 0.178 & 0.187 \\
Sig & 0.200 & 0.213 \\
\hline
\end{tabular}

Hasil pengujian normalitas data dengan one sample kolmogorov smirnov tes pada variabel prestasi belajar hasil uji menunjukkan nilai 0.178 dengan nilai signifikansi $0.200>\alpha 0.05$ (tabel 2) hal tersebut menunjukkan sebaran data prestasi belajar berdistribusi normal. Hasil yang sama juga pada data kesegaran jasmani yang menunjukkan sebaran data normal karena hasil uji menunjukkan 0.187 dengan nilai signifikansi $0.213>\alpha 0.05$ (tabel 2). 
Tabel 3. Uji Linieritas

\begin{tabular}{llcccc}
\hline & & df & F-hit & F-tab & Sig \\
\hline \multirow{2}{*}{$\begin{array}{l}\text { Prestasi Belajar* } \\
\text { Kesegaran Jasmani }\end{array}$} & $\begin{array}{l}\text { Linearity } \\
\text { Within Groups }\end{array}$ & 7 & & & \\
& Wrom & 19 & 0.635 & 2.54 & 0.721 \\
\hline
\end{tabular}

Hasil uji linieritas antar variable menunjukkan nilai deviation from linearity sig sebesar $0.721>\alpha 0.05$ (tabel 3) dan nilai F hitung $0.635<\mathrm{F}$ tabel 2.54 (tabel 3) sehingga disimpulkan terdapat hubungan yang linear antar variabel prestasi belajar dengan kesegaran jasmani siswa.

Tabel 4. Analisis Korelasi Kesegaran Jasmani Dengan Prestasi Akademik Siswa.

\begin{tabular}{lcc}
\hline \multicolumn{1}{c}{ Variabel } & $\mathbf{r}$ & $\rho^{*}$ \\
\hline $\begin{array}{l}\text { Hubungan tingkat kesegaran } \\
\text { jasmani terhadap prestasi belajar }\end{array}$ & 0.304 & 0.005 \\
siswa & & \\
\hline
\end{tabular}

r : Nilai Korelasi Antar Kedua Variabel, $P$ : Nilai Probabilitas

Hasil analisis uji korelasi spearman dengan nilai korelasi (r) 0,304 dengan tingkat probabilitas (0.005) $<\alpha=0.05$ hasil tersebut mengindikasikan ada hubungan tingkat kesegaran jasmani terhadap prestasi belajar siswa. Nilai korelasi 0,304 mengindikasikan bahwa besarnya korelasi antar variabel berada pada kategori cukup (tabel 4).

\section{Pembahasan}

Berdasarkan analisis hasil penelitian terdapat hubungan tingkat kesegaran jasmani terhadap hasil belajar siswa artinya secara umum dapat dikatakan bahwa semakin baik tingkat kesegaran jasmaninya maka semakin baik pula prestasi akademiknya. Hal tersebut sangat mungkin terjadi dikarenakan tingkat kesegaran jasmani dapat menunjang performa seseorang untuk beraktivitas baik fisik maupun dalam proses berpikir (Kyan et al., 2019). Apabila kesegaran jasmani seseorang rendah maka akan sangat mudah kelelahan sehingga tidak memaksimalkan fungsi otak dalam berpikir. Dalam kegiatan belajar tingkat kesegaran jasmani memegang peranan yang penting, apabila kesegaran jasmani siswa yang kurang baik maka akan berdampak pada aktivitas belajarnya yang pada akhirnya akan berpengaruh pada hasil belajarnya (Tucker et al., 2017).Siswa yang memiliki kesegaran jasmani yang kurang baik, maka akan mengalami kesulitan dalam aktivitas belajarnya ( $\mathrm{Gu}$ et al., 2016). Apabila kesegaran jasmani terjaga dengan baik maka proses pembelajaran yang dilakukan akan lebih maksimal, dari proses pembelajaran yang baik akan menghasilkan prestasi akademik yang gemilang.

Kesegaran jasmani yang berkaitan erat dengan kesehatan adalah daya tahan kardiovaskuler (Abdullah et al., 2017) dimana kemampuan ini menggambarkan kemampuan tubuh bekerja secara aerobic artinya kemampuan dan kesanggupan system peredaran darah dan pernafasan dalam mensuplai oksigen yang dibutuhkan keseluruh tubuh termasuk ke otak yang merupakan organ sentral dalam melakukan analisis berfikir.

Kesegaran jasmani dapat tercapai dengan rutin melakukan aktivitas fisik atau berolahraga. Aktivitas fisik mempunyai pengaruh terhadap lobus frontalis dimana terdapat pada suatu area di otak yang berfungsi sebagai konsentrasi mental dan perencanaan yang kedua fungsi tersebut berdampak pada hasil berfikir dari otak (Coe et al., 2006). Aktivitas otak bekerja secara kimiawi, zat kimia saraf yang dapat dihasilkan apabila melakukan aktivitas fisik dapat memicu tubuh untuk menghasilkan beberapa 
zat neurotransmiter diantaranya Norepinefrin dan serotonin yang berfungsi memperbaiki mood, motivasi dalam diri, kecemasan lebih rendah, percaya diri lebih tinggi dan memperbaiki proses belajar (Ratey, 2018).

Aktivitas fisik yang terstruktur dapat meningkatkan aliran darah ke otak sehingga sehingga nutrisi dan oksigen dapat tersalurkan dengan baik (Houdebine et al., 2017). Kurangnya oksigen pada otak mengakibatkan disorientasi, kelelahan, gangguan konsentrasi, bingung, dan masalah pada daya ingat. Aktivitas fisik yang baik mengakibatkan tak mencapai kondisi homeostasis, keseimbangan nutrisi dan zat-zat kimia otak yang memungkinkan otak siap melakukan proses analisis dan belajar (Stern et al., 2019).

Namun apabila aktivitas fisik jarang dilakukan dan mengakibatkan tingkat kebugaran jasmani rendah mengakibatkan tidak maksimalnya nutrisi dan oksigen yang mengalir ke otak yang mengakibatkan siswa tidak siap dalam melakukan proses belajar mengajar sehingga capaian prestasi belajar tidak maksimal pula, karena aktivitas fisik sangat berperan dalam mendukung pencapaian hasil belajar siswa (Álvarez-Bueno et al., 2017; Nayak B et al., 2016). Pengelolaan proses metakognitif sebagai dasar belajar anak juga harus memperhatikan beberapa hal diantaranya control emosi dengan membuat suasana yang senang dan bersemangat bagi siswa, control kognitif dengan menggunakan metode yang memacu proses berfikir siswa, dan yang terakhir control motoric dengan melibatkan gerak fisik sebagai bagian dalam pembelajaran sehingga juga dapat memberi dampak terhadap kesegaran jasmaninya (Fitri, 2017).

Hasil penelitian ini diharapkan dapat berimplikasi terhadap proses pembelajaran disekolah yang tidak hanya mengedepankan aktivitas didalam kelas namun mencoba dengan berbagai metode yang melibatkan aktivitas fisik yang diatur dengan mekanisme model pembelajaran yang baku.

\section{Simpulan dan Rekomendasi}

Berdasarkan hasil analisis dapat disimpulkan ada hubungan kesegaran jasmani terhadap prestasi akademik siswa SMANOR Tadulako Sulawesi Tengah dengan nilai korelasi (r) 0,304 probabilitas $(0.005)<\alpha=0.05$. Disarankan agar guru, pelatih dan siswa dapat memaksimalkan aktivitas fisik yang menunjang kesegaran jasmani sehingga dapat berdampak pada hasil belajar siswa. Selain itu program ekstrakurikuler yang lebih massif dan melibatkan banyak siswa sehingga kegiatan aktivitas fisik dapat terlaksana dan menunjang pencapaian kesegaran jasmani siswa yang lebih baik.

\section{Ucapan Terima Kasih:}

Kepada Fakultas Keguruan dan Ilmu Pendidikan Universitas Tadulako atas bantuan biaya penelitian.

\section{Daftar Pustaka:}

Abdullah, M. R., Hairi, M. S. N. A., Musa, R. M., Maliki, A. B. H. M., \& Kosni, N. A. (2017). Prediction of Specific Physical characteristic and Fitness Related Variables on Cardiovascular Endurance among some Selected Uniform Arm Units of University Sultan Zainal Abidin, Malaysia. Movement, Health \& Exercise, 6(1). https://doi.org/10.15282/mohe.v6i1.133.

Alamsyah, D. A. N., Hestiningsih, R., \& Saraswati, L. D. (2017). Faktor-Faktor Yang Berhubungan Dengan Kebugaran Jasmani Pada Remaja Siswa Kelas Xi Smk Negeri 11 Semarang. Jurnal Kesehatan Masyarakat (e-Journal), 5(3), 77-86.

Álvarez-Bueno, C., Pesce, C., Cavero-Redondo, I., Sánchez-López, M., Martínez-Hortelano, J. A., \& Martínez-Vizcaíno, V. (2017). The Effect of Physical Activity Interventions on Children's 
Cognition and Metacognition: A Systematic Review and Meta-Analysis. Journal of the American Academy of Child \& Adolescent Psychiatry, 56(9), 729-738. https://doi.org/10.1016/j.jaac.2017.06.012.

Arifin, Z. (2011). Penelitian Pendidikan Metode dan Paradigma Baru. PT. Remaja Rosdakarya.

Coe, D. P., Pivarnik, J. M., Womack, C. J., Reeves, M. J., \& Malina, R. M. (2006). Effect of Physical Education and Activity Levels on Academic Achievement in Children: Medicine \& Science in Sports \& Exercise, 38(8), 1515-1519. https://doi.org/10.1249/01.mss.0000227537.13175.1b.

Fitri, R. (2017). Metakognitif pada Proses Belajar Anak dalam Kajian Neurosains. Jurnal Pendidikan (Teori Dan Praktik), 2(1), 56. https://doi.org/10.26740/jp.v2n1.p56-64.

Gil, E. F. J., Chillón, P., Fernández-García, J. C., \& Cadenas-Sanchez, C. (2020). Association of Physical Fitness with Intelligence and Academic Achievement in Adolescents. International Journal of Environmental Research and Public Health, 17(12), 4362. https://doi.org/10.3390/ijerph17124362.

Gu, X., Chang, M., \& Solmon, M. A. (2016). Physical Activity, Physical Fitness, and Health-Related Quality of Life in School-Aged Children. Journal of Teaching in Physical Education, 35(2), 117-126. https://doi.org/10.1123/jtpe.2015-0110.

Han, G.-S. (2018). The relationship between physical fitness and academic achievement among adolescent in South Korea. Journal of Physical Therapy Science, 30(4), 605-608. https://doi.org/10.1589/jpts.30.605.

Houdebine, L., Gallelli, C. A., Rastelli, M., Sampathkumar, N. K., \& Grenier, J. (2017). Effect of physical exercise on brain and lipid metabolism in mouse models of multiple sclerosis. Chemistry and Physics of Lipids, 207, 127-134. https://doi.org/10.1016/j.chemphyslip.2017.06.002.

Humaedi, H., Iskandar, H., \& Abduh, I. (2019). Pengembangan Model Pembelajaran Outbound pada Pendidikan Jasmani dalam Meningkatkan Kesegaran Jasmani Siswa. Jurnal Inspirasi Pendidikan, 9(2), 117 - 122. http://dx.doi.org/ 10.21831.

Irhas, A., \& Anna, N. (2014). Hubungan Status Gizi Dan Aktivitas Fisik Dengan Tingkat Kebugaran Jasmani Siswa Sekolah Dasar (Studi Pada Siswa Kelas Ivb Dan V Mi Al Hikmah Gempol Manis). Jurnal Kesehatan Olahraga, 2(2).

Kyan, A., Takakura, M., \& Miyagi, M. (2019). Mediating effect of aerobic fitness on the association between physical activity and academic achievement among adolescents: A cross-sectional study in Okinawa, Japan. Journal of Sports Sciences, 37(11), 1242-1249. https://doi.org/10.1080/02640414.2018.1554552.

Md Azmi, K. N. E., \& Abdul Razak, M. R. (2020). Physical Fitness Based on Health and Its Relation to Body Mass Index (BMI) among FELDA Pupils in the Region of Kuantan, Pahang. International Journal of Advanced Research in Education and Society; Vol 2 No 1 (2020): Mar 2020. http://103.8.145.246/index.php/ijares/article/view/8936.

Nayak B, S., Miranda, S. A., Fitzrol, O. jon B., Anthony, L., Rao S, G., \& Aithal P, A. (2016). The Impact of Physical Activities on the Academic Performance of Medical Students. Online Journal of Health and Allied Sciences, 15(2), 1-4. 
Perez, J. (2019). The Relationship Between Physical Fitness \& Academic Acbievement in African-American High School Freshman Females. Texas A\&M University.

Pusat Pengembangan Kualitas Jasmani. (2010). TKJI Tes Kesegaran Jasmani Indonesia. Kementerian Pendidikan Nasional.

Ratey, J. (2018). The Revolutionary New Science of Exercise and Brain. Little Brown And Company.

Schober, P., Boer, C., \& Schwarte, L. A. (2018). Correlation Coefficients: Appropriate Use and Interpretation. Anesthesia \& Analgesia, 126(5), 1763-1768. https://doi.org/10.1213/ANE.0000000000002864.

Sepriadi, S., Hardiansyah, S., \& Syampurma, H. (2017). Perbedaan Tingkat Kesegaran Jasmani Berdasarkan Status Gizi. Jurnal Media Ilmu Keolahragaan Indonesia, 7(1), 25-34.

Singh, K., \& Bhatti, G. K. (2020). Effect of Physical Exercise Training to Improve Physical Fitness in Overweight Middle-Aged Women. International Journal of Scientific Research, 9(1), 6-9.

Stern, Y., MacKay-Brandt, A., Lee, S., McKinley, P., McIntyre, K., Razlighi, Q., Agarunov, E., Bartels, M., \& Sloan, R. P. (2019). Effect of aerobic exercise on cognition in younger adults: A randomized clinical trial. Neurology, 10.1212/WNL.0000000000007003. https://doi.org/10.1212/WNL.0000000000007003.

Tucker, H., Bebeley, S., \& Laggao, S. (2017). Children and Adolescents' Fitness Skill Level in Physical Activity: A Motivational Concern for Public Health Education. International Journal of Science and Research (IJSR), 6(11), 18-22. https://doi.org/10.21275/ART20177770.

Wahana, S. (2019). Hubungan Hidup Bersih dan Sehat dengan Tingkat Kebugaran Jasmani Siswa Kelas X di SMAN 2 Lamongan. JOSSAE: Journal of Sport Science and Education, 3(2), 103. https://doi.org/10.26740/jossae.v3n2.p103-111.

Welis, W., \& Muhamad, S. R. (2010). Giri Untuk Aktivitas Fisik dan Kebugaran. Sukabina Press.

Zhang, J., Zhang, J., Feng, Z., \& Guo, X. (2019). Residuals based Kolmogorov-Smirnov and Cramér-von Mises tests for varying coefficient models. Communications in Statistics - Simulation and Computation, 1-17. https://doi.org/10.1080/03610918.2018.1506031. 